\title{
Nutrition Society of New Zealand Annual Conference Held in Auckland, New Zealand, 28-30th November 2018
}

\author{
Rachel Brown 1,*, Sally Mackay ${ }^{2}$ and Helen Eyles 2,3 \\ 1 Department of Human Nutrition, University of Otago, Dunedin 9054, New Zealand \\ 2 Department of Epidemiology and Biostatistics, School of Population Health, Faculty of Medical and Health \\ Sciences, University of Auckland, Auckland 1072, New Zealand; sally.mackay@auckland.ac.nz (S.M.); \\ h.eyles@auckland.ac.nz (H.E.) \\ 3 National Institute for Health Innovation, School of Population Health, Tamaki Campus, University of \\ Auckland, Auckland 1072, New Zealand \\ * Correspondence: rachel.brown@otago.ac.nz; Tel.: +64-3-479-5839
}

Published: 4 March 2019

The annual conference and scientific meeting of the Nutrition Society of New Zealand took place in Albany, Auckland, New Zealand from 28-30th November 2018. The meeting comprised 4 plenary sessions, 3 concurrent oral sessions, and 23 posters, providing an opportunity for more than 68 nutritional scientists to present their research. Abstracts for plenary talks, oral presentations and posters are published here. The aim of the annual meeting is to foster discussion and disseminate the results of nutrition-related research undertaken by the members of the society.

The theme of the Nutrition Society of New Zealand in 2018 was "Finding the Balance - Te rapu I te pauna". The first plenary session included presentations on nutrition, health and sustainability in the NZ context by Dr Bevan Eruetel, Dr Daniel Hikuroa, and Emily King. The second plenary session included presentations on nutrition education by Associate Professor Clare Wall, Sarah Hanrahan, and Michelle Gibbs. The third plenary session included presentations on child health and sports nutrition by Emeritus Professor Lynne Daniels, Professor Rachael Taylor, and Professor David Rowlands. A fourth plenary session included a presentation on technology in nutrition by Professor Cliona Ni Mhurchu. The Muriel Bell Lecture entitled 'Power dynamics in 21st Century food systems' was given by Professor Boyd Swinburn of the Faculty of Medical and Health Sciences, University of Auckland.

C 2019 by the authors. Licensee MDPI, Basel, Switzerland. This article is an open access article distributed under the terms and conditions of the Creative Commons Attribution (CC BY) license (http://creativecommons.org/licenses/by/4.0/). 